\title{
A New Approach for Harmonic Distortion Minimization in Power Systems Supplying Nonlinear Loads
}

\author{
A. F. Zobaa, Senior Member, IEEE and S. H. E. Abdel Aleem, Member, IEEE
}

\begin{abstract}
In view of the many problems associated with harmonics pollution within industrial firms, the development of new passive and/or hybrid filtering techniques of higher quality, higher efficiency, and lower cost is a necessity for the forthcoming power quality age. This article suggests a hybrid passive filter, which consists of a certain combination of a shunt passive filter with a series passive portion, as a substitute to overcome the shortcomings of conventional shunt passive filtering techniques. Constrained optimization is used to find the optimal sizing of parameters of the hybrid passive filter in order to reduce both harmonic voltages and harmonic currents in the power system to an acceptable level, as well as to improve the load power factor. The optimal design of the hybrid passive filter and its feasibility are compared to those of the $C$-type passive filter and the conventional shunt passive filter by means of four study cases taken from existing publications. Several simulation results are shown in order to highlight the viability of the proposed filter.
\end{abstract}

Index Terms - Power systems harmonics, passive filters, power quality, harmonic distortions.

\section{INTRODUCTION}

The use of passive filters is preferred because of their simplicity, flexibility and economical cost. They are commonly classified according to harmonic suppression techniques into shunt and series passive filters. Series passive filters are given by parallel inductance and capacitance and are resonated at a specific harmonic order to put forward a high blocking impedance, and it is known that these kinds of filters must withstand the rated load current. Therefore they can generate notable losses and voltage drops at the fundamental frequency. Given the prominent cost of the series passive filters as well as their disadvantages, the actual technical and economical approach to current harmonics suppression is to use shunt passive filters (SPFs) [1]-[4].

SPFs present very a low impedance path at the resonant frequency and divert most of the harmonic current at that

Manuscript received January 25, 2013; revised July 14, 2013 and October 21, 2013; accepted November 27, 2013.

Copyright (C) 2013 IEEE. Personal use of this material is permitted. However, permission to use this material for any other purposes must be obtained from the IEEE by sending a request to pubs-permissions@ieee.org Dr. Ahmed F. Zobaa is with the School of Engineering and Design, Brunel University, Uxbridge, Middlesex, UB8 3PH, United Kingdom (e-mail: azobaa@ieee.org). Dr. Shady H. E. Abdel Aleem is with the $15^{\text {th }}$ of May, Higher institute of Engineering, Cairo, Egypt (e-mail: engyshady@ieee.org). frequency; however, the risk in passive filters' practical manipulation is still very serious, because of their dependence on the source impedance, which is not determined accurately, in addition to the possibility of occurrence of series and/or parallel resonance and distortion in the voltage at the point of common coupling (PCC). Recently, as well as the conventional shunt passive techniques, the $C$-type passive filter $(C P F)$ has been proposed, which has a good suppression at the tuned frequencies and does not result in a parallel resonance. Also, it is appropriate for randomly varying loads [5]-[8]. Unfortunately, it was clear from real practice that using SPFs or the recent CPFs improves the quality of voltage but cannot meet the requirements of the current harmonic component reduction. Consequently, in the last years, topologies combining different configurations of fixed passive and/or adaptive passive facilities have been developed. Recently, [3] introduced an adaptive hybrid system configuration, which consists of a series passive filter, a shunt passive filter, and a thyristor-controlled reactor (TCR), in order to solve the problems caused by using stand-alone passive filters, and removing the resonance that may occur, especially for variable-load reactive-power demand. Despite the valuable development added by such a hybrid filter, the most managed solution for power factor correction and harmonic compensation is still the fixed passive facility, mainly in the standing industrial firms.

In this paper, a suggested fixed hybrid passive filter is investigated as a combination between series and shunt passive topologies to minimize both harmonic voltages and currents in the power system to an acceptable level at the $P C C$, regardless of the source impedance, and also to improve the load power factor to a desired value $(\geq 90 \%)$. The technical and economic merits of the proposed hybrid passive filter (HPF) compared to the CPF presented in [6] and the SPF presented in [1] are discussed by means of different study cases.

The well-known optimization technique FFSQP (A FORTRAN code for solving optimization problems, possibly minimax, with general inequality constraints and linear equality constraints, generating feasible iterates) is used for the filter constrained optimal design. Recently, [6] examined the effect of this search code on the performance of the $C P F$, and the general search formulation was attractive, owing to the basic principle of sequential approximation in replacing the 
given nonlinear problem with a sequence of subproblems that are easier to solve. The quadratic programming subproblems are always consistent, i.e., a feasible solution always exists, and the objective function may be used directly as a merit function in the line search. Readers should refer to [6] and [9] for the exact formulations of the search algorithm using the FFSQP package.

\section{HyBrid PASSIVE FILTER TOPOLOGY}

Fig. 1 demonstrates a circuit model of the proposed HPF. The main feature of the HPF which differs from other passive features is its series components $L_{S E}$ and $C_{S E}$, which resonate at the fundamental frequency, and thus the fundamental current is permitted to pass freely under the influence of the shunt portion only. In other words, the series capacitor is sized so that the magnitude of its capacitive reactance is equal to the magnitude of the series inductive reactance at the fundamental frequency equals $X_{S E}$. Thus the filter acts as a conventional single tuned filter at the fundamental frequency with a small, additional, voltage drop in the series portion due to the not null resistance $R_{S E}$ of the series inductor. In practice, the internal resistance of a compensator reactor varies in the range of $1 \%$ up to $5 \%$ with respect to the magnitude of its fundamental reactance [10]. Actually, power dissipation in the compensator reactor, however small, will take place. As the frequency increases, the inductor $L_{S H}$ starts to resonate with $C_{S H}$ at a certain resonant frequency, which makes the filter act as a single-tuned filter with a blocking reactor. This series reactor provides adequate blocking impedance to reduce any current harmonics already presented. Accordingly, the shunt filter capacitor does not become overloaded. The series reactor also acts as an isolator between the power system and the drive and also isolates the possible influences of the line harmonic voltages on the load and filter. It prevents the parallel and the series resonance with the utility and/or other loads at the harmonic frequencies, (it moves the filter parallel resonance frequency away from prevailing current harmonics caused by nonlinear load). Therefore, there is no harmonic amplification, and, promisingly, it has a better current quality than other fixed passive filtering methods.

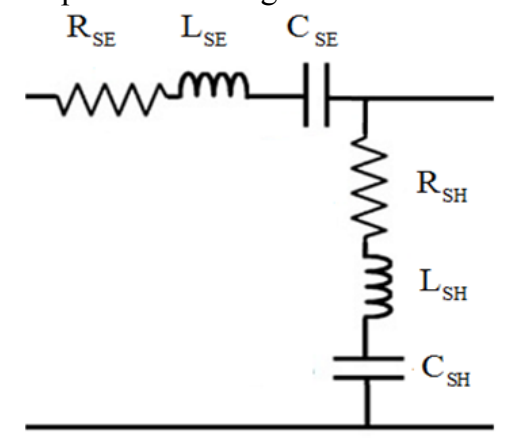

Fig.1. Proposed HPF equivalent circuit

The design of the HPF has been carried out in two stages: the design of the shunt branch impedance $Z_{H k}$ at the $k$ th harmonic order and the design of the series branch impedance $Z_{E k}$ at the $k$ th harmonic order forming a high blocking filter, as follows:

$$
\begin{aligned}
& Z_{\mathrm{Hk}}=\mathrm{R}_{\mathrm{SH}}+\mathrm{j}\left(\mathrm{kX}_{\mathrm{LSH}}-\frac{\mathrm{X}_{\mathrm{CSH}}}{\mathrm{k}}\right) \\
& \mathrm{Z}_{\mathrm{Ek}}=\mathrm{R}_{\mathrm{SE}}+\mathrm{j}\left(\mathrm{kX}_{\mathrm{LSE}}-\frac{\mathrm{X}_{\mathrm{CSE}}}{\mathrm{k}}\right)=\mathrm{R}_{\mathrm{SE}}+\mathrm{j} \mathrm{X}_{\mathrm{SE}}\left(\mathrm{k}-\frac{1}{\mathrm{k}}\right)
\end{aligned}
$$

The magnitude of the fundamental capacitive reactance of the shunt portion $X_{C S H}$ can be easily calculated if the fundamental reactive power supplied by the shunt portion capacitance $Q_{C 1}$ is known, also the magnitude of the inductive reactance of the shunt portion $X_{L S H}$ is related to $X_{C S H}$ by the shunt tuned harmonic order, $k^{*}$, as follows:

$$
\begin{aligned}
& \mathrm{X}_{\mathrm{CSH}}=\frac{\mathrm{k}^{2}}{\mathrm{k}^{2}-1}\left(\frac{\mathrm{V}_{\mathrm{L} 1}^{2}}{\mathrm{n}^{*} \mathrm{Q}_{\mathrm{L} 1}}\right)=\frac{\mathrm{k}^{2}}{\mathrm{k}^{2}-1}\left(\frac{\mathrm{V}_{\mathrm{L} 1}^{2}}{\mathrm{Q}_{\mathrm{C} 1}}\right) \\
& \mathrm{X}_{\mathrm{LSH}}=\frac{\mathrm{X}_{\mathrm{CSH}}}{\left(\mathrm{k}^{*}\right)^{2}}
\end{aligned}
$$

where: $V_{L 1}$ is the fundamental voltage at the shunt portion's bus. $Q_{L 1}$ is the fundamental reactive power demanded by the load and $n$ is a factor that allows incremental discrete steps of $Q_{C 1}$. It is commonly suggested in low voltage industrial applications that the step of $Q_{C 1}$ is 50 kvar [11]. Also, the shunt capacitor's nominal voltage is assumed to be equal to the fundamental source voltage $V_{S 1}$ to avoid the capacitor loading [10].

For the series portion design, it must be sized to carry the full feeder load; it must consume low reactive power and withstands the nominal system current $I_{S}$. At the same time, the series inductance $L_{S E}$ should be relatively large to enhance the current quality. Thus, the following have to be met:

1. At $\mathrm{k}=1 ; \mathrm{X}_{\mathrm{LSE}}=\mathrm{X}_{\mathrm{CSE}}=\mathrm{X}_{\mathrm{SE}}$,

2. $R_{S E}$ equals $1 \%$ with respect to $X_{S E}$ in order to maintain the additional voltage drop and joule losses as small as possible.

3. $\left|X_{S E}\right|$ is given in Equation (5); $m$ is an incremental factor varying with step of 0.01 , so that the reactive power consumed by the series portion is less than or equal $25 \%$ with respect to the fundamental reactive power demanded by the load [12], [13].

$\left|\mathrm{X}_{\mathrm{SE}}\right|=\mathrm{m} \frac{\mathrm{Q}_{\mathrm{L} 1}}{\mathrm{I}_{\mathrm{S}}^{2}}$

4. The series capacitor has been used for tuning the series reactor at the fundamental frequency, in order to minimize the fundamental voltage drop. From the harmonics point of view, it has noticeable effect on the frequency response at very low frequencies (subharmonics), but little or no effects at higher frequencies.

The shunt filter impedance equals $R_{S H}$ at the resonant frequency. Recalling the method presented in [6], the shunt resistance is designed by determination of the maximum percentage fraction of the current $\left(\mathrm{I}_{\mathrm{SPU}}\right)$ that is allowed to flow through the supply reactance and the blocking series portion, at the shunt tuned harmonic order, $k^{*}$. Therefore, 


$$
\mathrm{R}_{\mathrm{SH}}\left(\mathrm{k}^{*}\right)=\frac{\left(\mathrm{k}^{*} \mathrm{X}_{\mathrm{T}}+\mathrm{X}_{\mathrm{SE}}\left(\mathrm{k}^{*}-\frac{1}{\mathrm{k}^{*}}\right)\right)}{\sqrt{\left(\frac{1}{\mathrm{I}_{\mathrm{SPU}}\left(\mathrm{k}^{*}\right)}\right)^{2}-1}}
$$

The relationship among $\mathrm{R}_{\mathrm{SH}}$, quality factor (q), and bandwidth $\left(\mathrm{B}_{\mathrm{P}}\right)$ are:

$$
\mathrm{q}=\frac{\mathrm{k}^{*} \mathrm{X}_{\mathrm{LSH}}}{\mathrm{R}_{\mathrm{SH}}} \text {, and } \mathrm{B}_{\mathrm{P}}=\frac{\mathrm{k}^{*} \mathrm{f}_{1}}{\mathrm{q}}
$$

where $f_{1}$ is the fundamental frequency in $\mathrm{Hz}$.

\section{COMPENSATED SYSTEM CONFIGURATION AND HARMONIC RESONANCE CONSTRAINTS}

Fig. 2 shows the single phase equivalent circuit of the system configuration under study, where $R_{L}$ and $X_{L}$ are the magnitudes of load resistance and reactance, respectively, also, $R_{T}$ and $X_{T}$ are the magnitudes of the source resistance and reactance, all expressed in ohms at the fundamental frequency. The $k$ th harmonic Thevenin source impedance and the $k$ th harmonic load impedance are given as

$$
\begin{aligned}
& Z_{\mathrm{Tk}}=\mathrm{R}_{\mathrm{T}}+\mathrm{jk} \mathrm{X}_{\mathrm{T}} \\
& \mathrm{Z}_{\mathrm{Lk}}=\mathrm{R}_{\mathrm{L}}+\mathrm{jk} \mathrm{X}_{\mathrm{L}}
\end{aligned}
$$

Voltage source nonlinearity is represented in the source harmonic voltages as $V_{S k}$. Also, load nonlinearity is represented in harmonic load currents as $I_{L k}$ [6]. In order to maintain simplicity; the constant current source model is used for the representation of the nonlinear load. This model is usually placed in the analysis focused on resonance. According to [14], the constant current source model is adequate for the representation of the nonlinear loads under the non-sinusoidal voltage with total harmonic distortion on order of $10 \%$. $I_{S k}$ is the supply current at the $k$ th harmonic order, it is given as

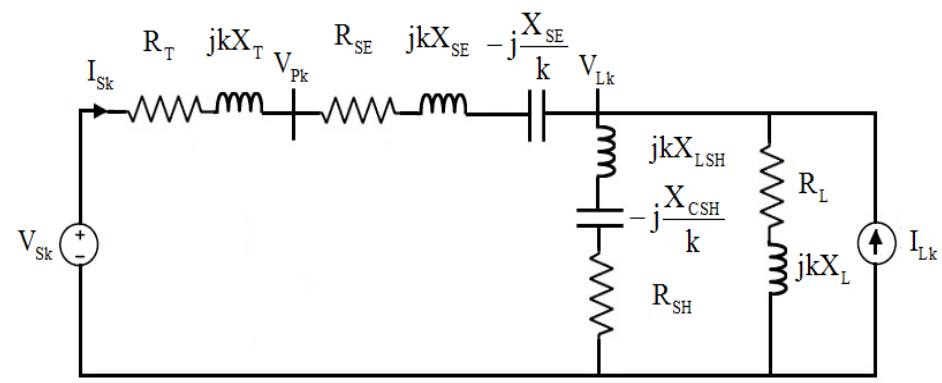

Fig.2. Configuration of the system under study

$$
\mathrm{I}_{\mathrm{Sk}}=\frac{\left[\mathrm{M}_{1}\right]+\mathrm{j}\left[\mathrm{M}_{2}\right]}{\left[\mathrm{P}_{1}\right]+\mathrm{j}\left[\mathrm{P}_{2}\right]}
$$

Also, the load voltage $V_{L k}$ and the compensated PCC voltage $V_{P k}$ at the $k$ th harmonic order are given as:

$$
\begin{gathered}
\mathrm{V}_{\mathrm{Lk}}=\frac{\left[\mathrm{N}_{1}\right]+\mathrm{j}\left[\mathrm{N}_{2}\right]}{\left[\mathrm{P}_{1}\right]+\mathrm{j}\left[\mathrm{P}_{2}\right]} \\
\mathrm{V}_{\mathrm{Pk}}=\frac{\left[\mathrm{Q}_{1}\right]+\mathrm{j}\left[\mathrm{Q}_{2}\right]}{\left[\mathrm{P}_{1}\right]+\mathrm{j}\left[\mathrm{P}_{2}\right]}
\end{gathered}
$$

where

$$
\begin{aligned}
& \mathrm{M}_{1}=\mathrm{V}_{\mathrm{Sk}}\left(\mathrm{R}_{\mathrm{SH}}+\mathrm{R}_{\mathrm{L}}\right)+\mathrm{I}_{\mathrm{Lk}} \mathrm{C}_{3}, \\
& \mathrm{M}_{2}=\mathrm{V}_{\mathrm{Sk}}\left(\mathrm{C}_{5}+\mathrm{k} \mathrm{X}_{\mathrm{L}}\right)+\mathrm{I}_{\mathrm{Lk}} \mathrm{C}_{4}, \\
& \mathrm{~N}_{1}=\mathrm{V}_{\mathrm{Sk}} \mathrm{C}_{3}-\mathrm{I}_{\mathrm{Lk}}\left(\mathrm{C}_{1} \mathrm{R}_{\mathrm{SH}}-\mathrm{C}_{2} \mathrm{C}_{5}-\mathrm{C}_{4} \mathrm{C}_{6}\right), \\
& \mathrm{N}_{2}=\mathrm{V}_{\mathrm{Sk}} \mathrm{C}_{4}-\mathrm{I}_{\mathrm{Lk}}\left(\mathrm{C}_{1} \mathrm{C}_{5}+\mathrm{C}_{2} \mathrm{R}_{\mathrm{SH}}+\mathrm{C}_{3} \mathrm{C}_{6}\right), \\
& \mathrm{Q}_{1}=\mathrm{V}_{\mathrm{Sk}}\left(\mathrm{C}_{3}-\mathrm{C}_{6}\left(\mathrm{C}_{5}+\mathrm{k} \mathrm{X}_{\mathrm{L}}\right)\right)-\mathrm{I}_{\mathrm{Lk}}\left(\mathrm{C}_{1} \mathrm{R}_{\mathrm{SH}}-\mathrm{C}_{2} \mathrm{C}_{5}\right), \\
& \mathrm{Q}_{2}=\mathrm{V}_{\mathrm{Sk}}\left(\mathrm{C}_{4}+\mathrm{C}_{6}\left(\mathrm{R}_{\mathrm{SH}}+\mathrm{R}_{\mathrm{L}}\right)\right)-\mathrm{I}_{\mathrm{Lk}}\left(\mathrm{C}_{1} \mathrm{C}_{5}+\mathrm{C}_{2} \mathrm{R}_{\mathrm{SH}}\right), \\
& \mathrm{P}_{1}=\left(\mathrm{C}_{1}+\mathrm{R}_{\mathrm{SH}}\left(\mathrm{R}_{\mathrm{T}}+\mathrm{R}_{\mathrm{L}}\right)\right)-\left(\mathrm{C}_{5} \mathrm{X}_{\mathrm{TL}}\right)-\left(\mathrm{C}_{6}\left(\mathrm{C}_{5}+\mathrm{k} \mathrm{X}_{\mathrm{L}}\right)\right), \\
& \mathrm{P}_{2}=\left(\mathrm{C}_{2}+\mathrm{R}_{\mathrm{SH}} \mathrm{X}_{\mathrm{TL}}\right)+\left(\mathrm{C}_{5}\left(\mathrm{R}_{\mathrm{T}}+\mathrm{R}_{\mathrm{L}}\right)\right)+\left(\mathrm{C}_{6}\left(\mathrm{R}_{\mathrm{L}}+\mathrm{R}_{\mathrm{SH}}\right)\right) \\
& \mathrm{C}_{1}=\mathrm{R}_{\mathrm{T}} \mathrm{R}_{\mathrm{L}}-\mathrm{k}^{2} \mathrm{X}_{\mathrm{T}} \mathrm{X}_{\mathrm{L}}, \mathrm{C}_{2}=\mathrm{R}_{\mathrm{T}} \mathrm{kX} \mathrm{X}_{\mathrm{L}}+\mathrm{R}_{\mathrm{L}} \mathrm{k} \mathrm{X}_{\mathrm{T}}, \\
& \mathrm{C}_{3}=\mathrm{R}_{\mathrm{SH}} \mathrm{R}_{\mathrm{L}}-\mathrm{C}_{5} \mathrm{k} \mathrm{X}_{\mathrm{L}}, \mathrm{C}_{4}=\mathrm{R}_{\mathrm{SH}} \mathrm{kX} \mathrm{X}_{\mathrm{L}}+\mathrm{C}_{5} \mathrm{R}_{\mathrm{L}}, \\
& \mathrm{C}_{5}=\mathrm{kX} \mathrm{XSH}_{\mathrm{LSH}}-\frac{\mathrm{X}_{\mathrm{CSH}}}{\mathrm{k}}, \mathrm{C}_{6}=\mathrm{X}_{\mathrm{SE}}\left(\mathrm{k}-\frac{1}{\mathrm{k}}\right), \mathrm{X}_{\mathrm{TL}}=\mathrm{k}\left(\mathrm{X}_{\mathrm{T}}+\mathrm{X}_{\mathrm{L}}\right) .
\end{aligned}
$$

The resonance countermeasure is an important factor in harmonic passive filters design. Resonance values can be derived as shown below [15], [16].

\section{A. Voltage resonance (series resonance) condition}

For the system under study shown in Fig. 2, the $k$ th source side Thevenin impedance is given as,

$$
\mathrm{Z}_{\mathrm{k}}=\mathrm{Z}_{\mathrm{Tk}}+\mathrm{Z}_{\mathrm{Ek}}+\left(\mathrm{Z}_{\mathrm{Lk}} / / \mathrm{Z}_{\mathrm{Hk}}\right)
$$

where // means "in parallel with". Setting its imaginary component equals to zero, simplifying, and considering the load resistance and/or reactance large enough [10]; the voltage resonance equation can be approximated as:

$$
\left(\mathrm{kX}_{\mathrm{T}}+\mathrm{X}_{\mathrm{SE}}\left(\mathrm{k}-\frac{1}{\mathrm{k}}\right)\right)+\left(\mathrm{kX}_{\mathrm{LSH}}\right)-\frac{\mathrm{X}_{\mathrm{CSH}}}{\mathrm{k}}=0
$$

This represents the resonance between combination of the source impedance and the series portion impedance with the shunt compensator.

\section{B. Current resonance (Parallel resonance) condition}

As the total susceptance $\left(B_{k}\right)$ of the proposed compensator with the system circuit at harmonic order $k$ becomes zero, parallel current resonance can be occurred, $B_{k}$ is given as

$$
\begin{aligned}
& \mathrm{B}_{\mathrm{k}}=\frac{\left(\mathrm{X}_{\mathrm{SE}} / \mathrm{k}\right)-\mathrm{k}\left(\mathrm{X}_{\mathrm{T}}+\mathrm{X}_{\mathrm{SE}}\right)}{\left(\mathrm{R}_{\mathrm{T}}^{2}+\mathrm{R}_{\mathrm{SE}}^{2}\right)+\left(\mathrm{k}\left(\mathrm{X}_{\mathrm{T}}+\mathrm{X}_{\mathrm{SE}}\right)-\left(\mathrm{X}_{\mathrm{SE}} / \mathrm{k}\right)\right)^{2}} \\
&-\frac{\mathrm{kX}_{\mathrm{L}}}{\mathrm{R}_{\mathrm{L}}^{2}+\mathrm{k}^{2} \mathrm{X}_{\mathrm{L}}^{2}}-\frac{\mathrm{kX}_{\mathrm{LSH}}-\mathrm{X}_{\mathrm{CSH}} / \mathrm{k}}{\mathrm{R}_{\mathrm{SH}}^{2}+\left(\mathrm{kX}_{\mathrm{LSH}}-\mathrm{X}_{\mathrm{CSH}} / \mathrm{k}\right)^{2}}
\end{aligned}
$$

Thus a current resonance constraint is recognized so that $\left(\mathrm{B}_{\mathrm{k}} \geq\right.$ $0)$ at any adjacent harmonic order. Simplifying and solving (15); unwanted current resonant harmonic orders can be passed over [2].

\section{Cost estimation}

Ref. [10] describes the method for the evaluation of the parameters of the conventional shunt compensator for nonlinear loads, taking into account cost constraints. Thus, the total cost of the HPF (TCOST) can be calculated as follows:

$\mathrm{TCOST}=\mathrm{C}_{\mathrm{C}}+\mathrm{C}_{\mathrm{L}}+\mathrm{S}_{\mathrm{C}}+\mathrm{S}_{\mathrm{L}}$ 
so that

$$
\begin{aligned}
& \mathrm{C}_{\mathrm{C}}=\mathrm{U}_{\mathrm{C}} *\left[\mathrm{I}_{\mathrm{Ck}}^{2}\right]^{1 / 2} *\left[\sum_{\mathrm{k}} \mathrm{I}_{\mathrm{Ck}} \frac{\mathrm{X}_{\mathrm{CSH}}}{\mathrm{k}}\right] \\
& \mathrm{C}_{\mathrm{L}}=\mathrm{U}_{\mathrm{L}} *\left[\mathrm{I}_{\mathrm{Ck}}^{2}\right]^{1 / 2} *\left[\sum_{\mathrm{k}} \mathrm{I}_{\mathrm{Ck}} \mathrm{kX} \mathrm{LSH}_{\mathrm{CH}}\right] \\
& \mathrm{S}_{\mathrm{C}}=\mathrm{U}_{\mathrm{C}} *\left[\mathrm{I}_{\mathrm{Sk}}^{2}\right]^{1 / 2} *\left[\sum_{\mathrm{k}} \mathrm{I}_{\mathrm{Sk}} \frac{\mathrm{X}_{\mathrm{CSH}}}{\mathrm{k}}\right] \\
& \mathrm{S}_{\mathrm{L}}=\mathrm{U}_{\mathrm{L}} *\left[\mathrm{I}_{\mathrm{Sk}}^{2}\right]^{1 / 2} *\left[\sum_{\mathrm{k}} \mathrm{I}_{\mathrm{Sk}} \mathrm{kX}_{\mathrm{LSH}}\right]
\end{aligned}
$$

The harmonic voltages are added linearly in Equations (17) (20) in the first summation to emphasize the effect of the resultant peak (as opposed to rms) voltage on compensator cost [17], where $\left(C_{C}, C_{L}\right)$ are the shunt capacitor and reactor costs and $\left(S_{C}, S_{L}\right)$ are the series capacitor and reactor costs, all expressed in dollars. Also, $I_{C k}$ is the shunt capacitor current at harmonic order $k$, and is given as

$$
\mathrm{I}_{\mathrm{Ck}}=\frac{\mathrm{V}_{\mathrm{Lk}}}{\mathrm{Z}_{\mathrm{Hk}}}
$$

where $U_{C}$ and $U_{L}$ are the unit costs of the capacitor and the reactor respectively, and are considered to be constant parameters. In order to maintain simplicity, it is assumed that the unit costs of the capacitors and the reactors are equal, so that, $U_{C}=U_{L}=U \$ /$ kvar [18].

\section{Formulation OF THE OBJective Optimization}

In typical practical power systems, current distortion is much higher than voltage distortion. This mirrors the basic concern of IEEE 519-1992 [19], in which the higher total harmonic current distortion ITHD reflects the total harmonic voltage distortion VTHD, leading to its increment at the PCC. However, according to the method adopted [20], the most accurate harmonic pollution formula (H.P) can be defined as:

$$
\text { H.P }=\sqrt{\text { VTHD }^{2}+\mathrm{ITHD}^{2}+\left(\mathrm{VTHD}^{*} \text { ITHD }\right)^{2}}
$$

The fitness of power harmonic filters for both harmonic currents and voltages can be evaluated from such a measurement. Besides, the harmonic resonant constraint, other additional constraints can be summarized as follows:

- According to IEEE 519-1992 [19], VTHD for voltage level up to $69 \mathrm{kV}$ is less than or equal to $5.0 \%$. Each individual harmonic voltage is limited to $3 \%$. ITHD should be limited to a standard percent according to the system $\left(\mathrm{I}_{\mathrm{SC}} / \mathrm{I}_{\mathrm{L}}\right)$ ratio.

- The shunt capacitor will be capable of continuous operation, provided that none of the following limitations are exceeded [11]: 135\% of nominal rms current based on rated $k V A$ and rated voltage, $110 \%$ of rated rms voltage, $120 \%$ of rated peak voltage, and $135 \%$ of nameplate kvar.

- Maintaining the values of displacement power factor Dpf and the load power factor $P F$ within an acceptable specified range ( $\geq 90 \%)$ is desired.

Thus, the object function for HPF optimization, complying with the previous constraints, is presented as:
Minimize H.P $\left(X_{C S H}, X_{L S H}, R_{S H}\right.$, and $\left.X_{S E}\right)$, subject to: $\left(X_{C S H}\right.$, $X_{L S H}, R_{S H}$, and $X_{S E}$ ) not being part of Equations (14) and (15). Taking the solutions of these equations, the pre-considered compensator values are used to subdivide the entire search region into smaller regions. In each region, total minima are detected, leading to the final detection of the global minimum of the (H.P) ratio.

\section{CASE Studies AND Results}

Table I shows four cases primarily taken from [19] of two different short-circuit capacities $\left(\mathrm{MVA}_{\mathrm{SC}}\right)$ of an industrial firm. The system data for equivalent single-phase mode are: The inductive loads power $=1700 \mathrm{~kW}$, the inductive loads reactive power $=1655 \mathrm{kvar}$, and the 60 - cycle supply phase voltage $=2.4 \mathrm{kV}$. Uncompensated system results are shown in Table II for comparison with HPF compensation results, where: $I_{S}, V_{L}$, and $V_{P}$ are the rms values of the supply current, load voltage, and $P C C$ voltage, respectively.

TABLE I

SYSTEM CASES [6]

\begin{tabular}{c|c|c|c|c}
\hline \hline Cases/Parameters & Case I & Case II & Case III & Case IV \\
\hline $\mathrm{MVA}_{\mathrm{SC}}$ & \multicolumn{2}{|c|}{80} & \multicolumn{2}{|c}{150} \\
\hline $\mathrm{R}_{\mathrm{T}}(\Omega)$ & 0.02163 & 0.02163 & 0.01154 & 0.01154 \\
\hline $\mathrm{X}_{\mathrm{T}}(\Omega)$ & 0.2163 & 0.2163 & 0.1154 & 0.1154 \\
\hline $\mathrm{R}_{\mathrm{L}}(\Omega)$ & 1.7421 & 1.7421 & 1.7421 & 1.7421 \\
\hline $\mathrm{X}_{\mathrm{L}}(\Omega)$ & 1.696 & 1.696 & 1.696 & 1.696 \\
\hline $\mathrm{V}_{\mathrm{S} 1}(\mathrm{~V})$ & 2400 & 2400 & 2400 & 2400 \\
\hline $\mathrm{V}_{\mathrm{S} 5}\left(\% \mathrm{~V}_{\mathrm{S} 1}\right)$ & 4.00 & 4.00 & 4.00 & 4.00 \\
\hline $\mathrm{V}_{\mathrm{S} 7}\left(\% \mathrm{~V}_{\mathrm{S} 1}\right)$ & 3.00 & 3.00 & 3.00 & 3.00 \\
\hline $\mathrm{V}_{\mathrm{S} 11}\left(\% \mathrm{~V}_{\mathrm{S} 1}\right)$ & 2.00 & 2.00 & 2.00 & 2.00 \\
\hline $\mathrm{V}_{\mathrm{S} 13}\left(\% \mathrm{~V}_{\mathrm{S} 1}\right)$ & 1.00 & 1.00 & 1.00 & 1.00 \\
\hline $\mathrm{I}_{\mathrm{L} 1}(\mathrm{~A})$ & 922.56 & 922.56 & 951.93 & 951.93 \\
\hline $\mathrm{I}_{\mathrm{L} 5}(\mathrm{~A})$ & 150 & 200 & 150 & 200 \\
\hline $\mathrm{I}_{\mathrm{L} 7}(\mathrm{~A})$ & 100 & 150 & 100 & 150 \\
\hline $\mathrm{I}_{\mathrm{L} 11}(\mathrm{~A})$ & 60 & 60 & 60 & 60 \\
\hline $\mathrm{I}_{\mathrm{L} 13}(\mathrm{~A})$ & 30 & 30 & 30 & 30 \\
\hline \hline
\end{tabular}

The system analysis has been evaluated for different study system configurations that indicate the system performance with the proposed HPF, as shown in Table III. Furthermore, Tables IV and $\mathrm{V}$ show the performance of the CPF design presented in [6] and the traditional SPF design presented in [1], respectively, in order to show the effectiveness of the $H P F$ in harmonic mitigation.

TABLE II

SYSTEM RESULTS BEFORE COMPENSATION [6]

\begin{tabular}{c|c|c|c|c}
\hline \hline Cases/Parameters & I & II & III & IV \\
\hline PF (\%) & 69.96 & 68.79 & 70.17 & 69.12 \\
\hline Dpf (\%) & 71.65 & 71.65 & 71.65 & 71.65 \\
\hline $\mathrm{I}_{\mathrm{S}}(\mathrm{A})$ & 938.71 & 951.41 & 969.35 & 983.01 \\
\hline $\mathrm{V}_{\mathrm{L}}(\mathrm{V})$ & 2259.34 & 2267.86 & 2321.78 & 2324.39 \\
\hline H.P (\%) & 22.36 & 29.30 & 20.80 & 27.38 \\
\hline \hline
\end{tabular}


TABLE III

RESULTS FOR THE PROPOSED HPF

\begin{tabular}{c|c|c|c|c}
\hline \hline Cases/Parameters & I & II & III & IV \\
\hline $\mathrm{X}_{\mathrm{CSH}}(\Omega)$ & 2.937 & 2.700 & 3.469 & 2.701 \\
\hline $\mathrm{X}_{\mathrm{LSH}}(\Omega)$ & 0.087 & 0.081 & 0.113 & 0.079 \\
\hline $\mathrm{R}_{\mathrm{SH}}(\Omega)$ & 0.012 & 0.019 & 0.028 & 0.023 \\
\hline $\mathrm{X}_{\mathrm{SE}}(\Omega)$ & 0.548 & 0.574 & 0.280 & 0.308 \\
\hline $\mathrm{R}_{\mathrm{SE}}(\Omega)$ & 0.005 & 0.005 & 0.002 & 0.003 \\
\hline $\mathrm{PF}(\%)$ & 97.11 & 94.27 & 98.64 & 93.90 \\
\hline $\mathrm{Dpf}(\%)$ & 97.23 & 94.38 & 99.08 & 94.24 \\
\hline $\mathrm{I}_{\mathrm{S}}(\mathrm{A})$ & 730.79 & 757.75 & 714.23 & 757.50 \\
\hline $\mathrm{V}_{\mathrm{P}}(\mathrm{V})$ & 2410.52 & 2431.51 & 2393.28 & 2418.29 \\
\hline $\mathrm{V}_{\mathrm{L}}(\mathrm{V})$ & 2409.29 & 2429.11 & 2392.31 & 2416.92 \\
\hline H.P $(\%)$ & 4.98 & 4.87 & 9.49 & 8.56 \\
\hline \hline \multicolumn{5}{|l}{}
\end{tabular}

TABLE IV

RESULTS FOR THE CPF PRESENTED IN [6]

\begin{tabular}{c|c|c|c|c}
\hline \hline Cases/Parameters & I & II & III & IV \\
\hline $\mathrm{X}_{\mathrm{CM}}(\Omega)$ & 2.700 & 2.700 & 2.700 & 2.701 \\
\hline $\mathrm{X}(\Omega)$ & 0.153 & 0.129 & 0.19 & 0.162 \\
\hline $\mathrm{R}(\Omega)$ & 100.00 & 100.00 & 75.00 & 75.00 \\
\hline $\mathrm{PF}(\%)$ & 95.37 & 95.26 & 94.38 & 93.87 \\
\hline $\mathrm{Dpf}(\%)$ & 96.22 & 96.22 & 96.22 & 96.22 \\
\hline $\mathrm{I}_{\mathrm{S}}(\mathrm{A})$ & 748.30 & 749.19 & 753.14 & 757.20 \\
\hline $\mathrm{V}_{\mathrm{L}}(\mathrm{V})$ & 2424.50 & 2424.38 & 2415.37 & 2415.38 \\
\hline $\mathrm{H} . \mathrm{P}(\%)$ & 13.34 & 14.20 & 19.89 & 22.51 \\
\hline \hline
\end{tabular}

TABLE V

RESULTS FOR THE SPF PRESENTED IN [1]

\begin{tabular}{c|c|c|c|c}
\hline \hline Cases/Parameters & I & II & III & IV \\
\hline $\mathrm{X}_{\mathrm{C}}(\Omega)$ & 4.844 & 4.383 & 4.205 & 4.786 \\
\hline $\mathrm{X}_{\mathrm{F}}(\Omega)$ & 0.209 & 0.174 & 0.223 & 0.211 \\
\hline $\mathrm{R}(\Omega)$ & 0.017 & 0.015 & 0.016 & 0.017 \\
\hline $\mathrm{PF}(\%)$ & 95.91 & 97.11 & 96.73 & 94.24 \\
\hline $\mathrm{Dpf}(\%)$ & 96.96 & 98.37 & 98.93 & 97.16 \\
\hline $\mathrm{I}_{\mathrm{S}}(\mathrm{A})$ & 719.86 & 714.24 & 724.81 & 741.18 \\
\hline $\mathrm{V}_{\mathrm{L}}(\mathrm{V})$ & 2346.25 & 2357.05 & 2382.53 & 2373.72 \\
\hline $\mathrm{H} . \mathrm{P}(\%)$ & 14.86 & 16.14 & 21.48 & 25.09 \\
\hline \hline
\end{tabular}

Comparison of the results given in Tables II to V shows that the optimization results are acceptable, providing an efficient system performance. Also, for the main target (H.P) suggested by [20] for the effectiveness of harmonic filters, it is obvious that installing the proposed HPF causes a remarkable reduction in the harmonic pollution ratio. This can be considered as a good sign for the significant fitness of the proposed hybrid passive filter in harmonic suppression. Thus the quality of the electrical system can be improved considerably. Fig. 3 shows that the total harmonic current distortion value of the compensated supply current is reduced to an acceptable limit, which could not be easily reached before with the conventional SPFs. This is considered to be a new contribution of the proposed hybrid passive filter. Figs. 4 and 5 show the simulated results of the optimization process of the compensated supply current harmonics content for cases I and III, respectively. The main contribution of the suggested method consists of the lower harmonic pollution of the supply current, compared to the response of the conventional SPF. Moreover, the HPF has a good capability for mitigation of the harmonic voltage distortion below the standard limits in all cases, as shown in Fig. 6 for the VTHD indication of the compensated load voltage and Figs. 7 and 8 for the values of the compensated load voltage harmonics content in cases I and III, respectively.

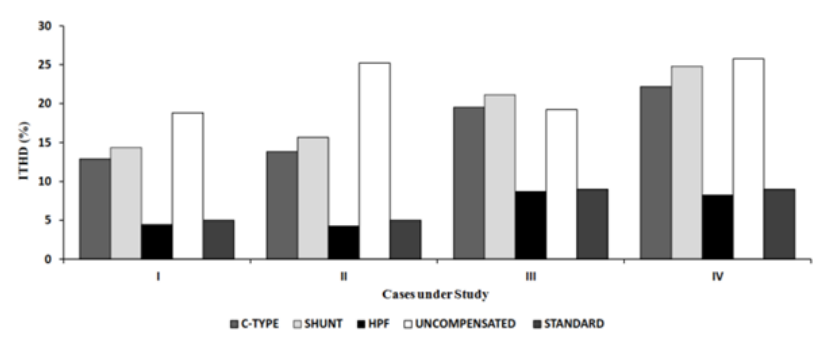

Fig.3. Total harmonic current distortion indication

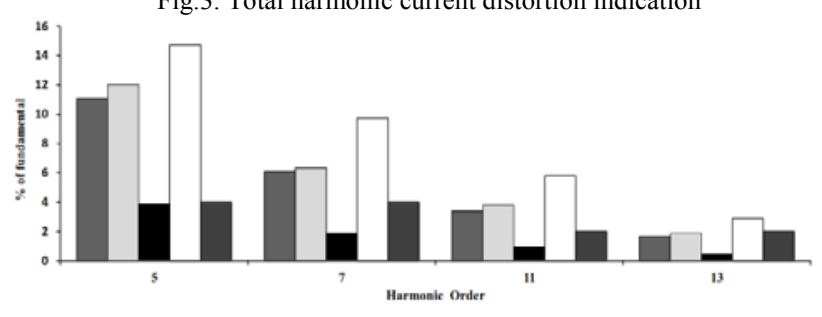

Fig.4. Compensated supply current' harmonic components: Case I

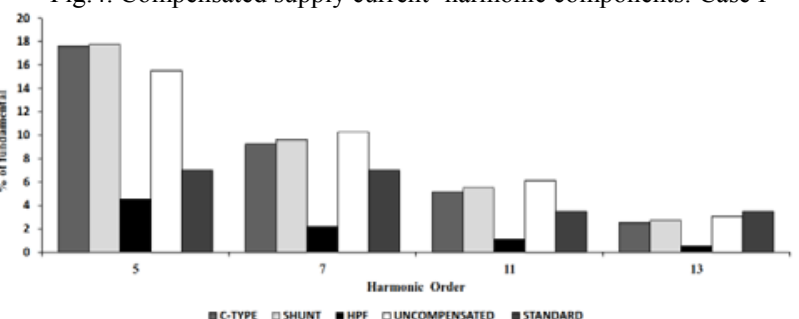

Fig.5. Compensated supply current' harmonic components: Case III

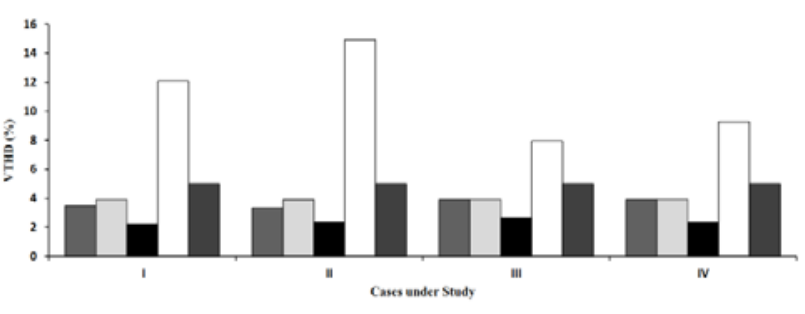

Fig.6. Total harmonic voltage distortion indication

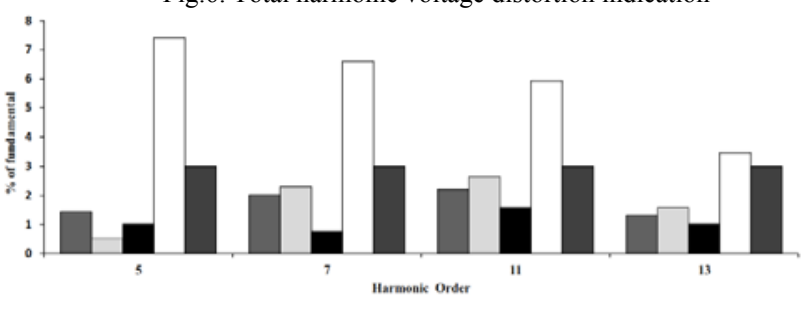

Fig.7. Compensated load voltage' harmonic components: Case I

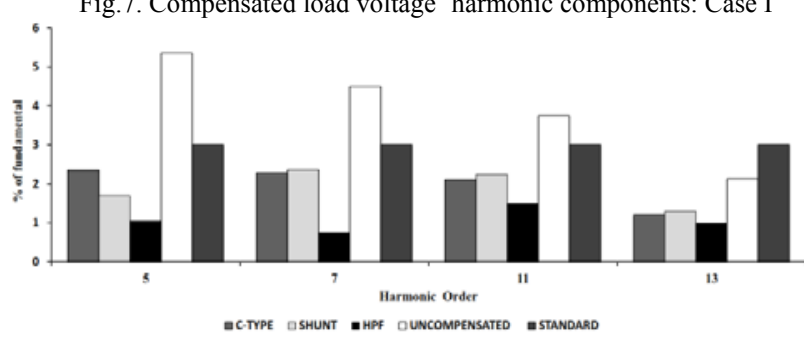

Fig.8. Compensated load voltage' harmonic components: Case III 
Checking the voltage at the PCC, it is obvious that the PCC voltage complies with the limits in the IEEE Std. 519 (approximately equals $3.85 \%$ in all cases), as shown in Fig. 9, for all cases under study.

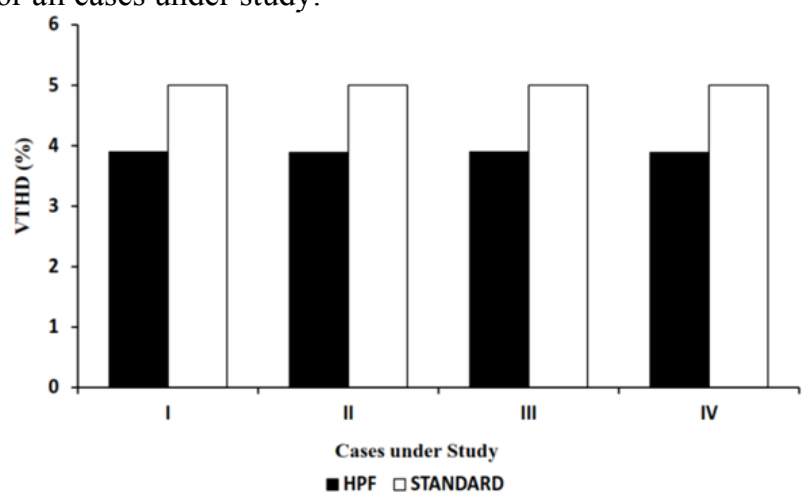

Fig.9. Total harmonic voltage distortion indication at the PCC

Referring to the capacitor loading constraints, it is notable that all values lie within the standard limits, as shown in Table VI, for all cases under study. If the resultant values are greater than standard limits, it is a good idea to use capacitors with a higher voltage rating [17].

TABLE VI

SHUNT CAPACITOR LOADING CONSTRAINTS

\begin{tabular}{|c|c|c|c|}
\hline Parameters & Calculated (\%) & Limit (\%) & Exceeds Limit \\
\hline \multicolumn{4}{|c|}{ Case I } \\
\hline Rms voltage & 103.29 & 110 & No \\
\hline Peak voltage & 109.74 & 120 & No \\
\hline Rms current & 106.03 & 135 & No \\
\hline kvar & 116.36 & 135 & No \\
\hline \multicolumn{4}{|c|}{ Case II } \\
\hline Rms voltage & 104.30 & 110 & No \\
\hline Peak voltage & 112.03 & 120 & No \\
\hline Rms current & 108.28 & 135 & No \\
\hline kvar & 120.31 & 135 & No \\
\hline \multicolumn{4}{|c|}{ Case III } \\
\hline Rms voltage & 103.06 & 110 & No \\
\hline Peak voltage & 110.66 & 120 & No \\
\hline Rms current & 106.96 & 135 & No \\
\hline kvar & 118.36 & 135 & No \\
\hline \multicolumn{4}{|c|}{ Case IV } \\
\hline Rms voltage & 103.71 & 110 & No \\
\hline Peak voltage & 111.63 & 120 & No \\
\hline Rms current & 107.92 & 135 & No \\
\hline kvar & 120.53 & 135 & No \\
\hline
\end{tabular}

Based on the various models presented for constrained harmonic pollution minimization for nonlinear loads, it is obvious that, for equal $\mathrm{MVA}_{\mathrm{SC}}$ systems with additional load current harmonics content, the reactive power supplied by the capacitor will increase, which will be reflected in the investment cost. The results shown in Table VI indicate that the capacitor loading requirements will be more stressed [6].

Lower MVA $_{\mathrm{SC}}$ systems with the same harmonic content will result in a lower ITHD level and harmonic pollution ratio owing to the great reduction in the current harmonics content. This is because of the additional series element of the HPF, which provides damping for the perturbations that can occur, which, in turn, improves the system stability.
For the proposed filter $H P F$, although it has similar structure to the conventional SPF, has a different operating principle. Unlike $S P F S$ that employs a single tuned filter for each dominant harmonic to be mitigated, HPF employs only one shunt branch per phase and the filter absorbs a broad range of dominant harmonics. Table VII shows a comparison between the shunt portion of the HPF and the SPF, considering their quality factors and their corresponding bandwidth $\left(\mathrm{B}_{\mathrm{P}}\right)$. It is obvious that the HPF has much broader $B_{P}$ than the conventional $S P F$.

TABLE VII

COMPARISON OF SPF AND HPF, CONSIDERING $Q$ AND $B_{P}$

\begin{tabular}{c|c|c|c|c}
\hline \hline Cases/Parameters & I & II & III & IV \\
\hline \multicolumn{5}{|c|}{$H P F$} \\
\hline $\mathrm{q}$ & 39.08 & 23.83 & 22.12 & 20.02 \\
\hline $\mathrm{B}_{\mathrm{P}}(\mathrm{Hz})$ & 8.93 & 14.64 & 15.01 & 17.54 \\
\hline $\mathrm{q}$ & $\mathrm{SPF}$ \\
\hline $\mathrm{B}_{\mathrm{P}}(\mathrm{Hz})$ & 59.57 & 60.44 & 59.63 & 59.59 \\
\hline \hline
\end{tabular}

Seeking clear demonstration of the proposed filter; performance of $H P F$ for the parameter values given in Table III is simulated using software package of MatLab program. Figs. 10 and 11 show the waveforms of the supply current, load voltage, before compensation in case II, and case IV, respectively, while Figs. 12 and 13 show them after compensation, in addition to the voltage at PCC $\left(\mathrm{V}_{\mathrm{P}}\right)$. It is obvious the remarkable reduction in the waveforms distortion. Fig. 14 shows filter impedance characteristics seen from the load side, for addressed cases, respectively, while, Fig. 15 shows the $k$ th source side Thevenin impedance $Z_{k}$, series impedance $\left(Z_{\mathrm{Tk}}+Z_{\mathrm{Ek}}\right)$ and the shunt portion impedance $Z_{H k}$ characteristics, for the same addressed cases. The tuning frequency of the shunt portion is between the 5th and 7th harmonic and the performance is not significantly dependent on it. Thus, the dominant harmonics are absorbed by the shunt portion on a broad range. The parallel resonance frequency of the HPF is a little below $140 \mathrm{~Hz}$ in cases I and II, and a little above $140 \mathrm{~Hz}$ in cases III and IV, thus the HPF exhibits only one resonance point safely above the second harmonic (which is greatly not likely to be excited). Fig. 15 shows that the series resonance frequency of the HPF is safely between the second and the third harmonic in the addressed cases. In the dominant harmonic frequency range; $H P F$ and $S P F$ have similar low impedance values. Additionally, Figs. 16 and 17 show the fast Fourier transform (FFT) analysis of the voltage at $P C C$ for the addressed cases; it is notable that all values lie within the standard limits.

In a running plant, it is well-known that the switching inrush current of a transformer is rich in even and third harmonics. Also, source voltage harmonic contents may change [21], [22]; thus, eight additional scenarios are examined for the HPF parameters given in Table III: Case I; as follows: 
Scenarios 1 to 4: considering an additional source voltage harmonic content of $3 \%$ to: $V_{S 2}, V_{S 3}, V_{S 4}$, and $V_{S 6}$ respectively. Scenarios 5 to 8: considering an additional load current harmonic content of 30 amperes to: $I_{L 2}, I_{L 3}, I_{L 4}$, and $I_{L 6}$, respectively.

In a similar situation with SPFs, it is expected that the magnified currents can give rise to large harmonic voltages and shunt capacitors could also fail prematurely. Fig. 18 shows the variation of the VTHD at the PCC, and the ITHD of the source current, while considering the previous scenarios. It is obvious that almost $1 \%$ change occurs in the VTHD at the PCC, thus maintaining the allowable voltage quality, additionally, no substantial current harmonic amplification; also, it has a better total current distortion percent than SPF, subjected to the same conditions (although that the HPF's efficiency is lowest at $\mathrm{k}=2$ ). Furthermore, none of the shunt capacitor loading limits are exceeded with respect to the previous scenarios, as shown in Fig. 19 for the shunt capacitor duties, so no overloading occurs in the shunt capacitor.

The HPF series impedance isolates the effects of the line harmonic voltages on the load and the shunt portion of the filter. Furthermore, it attenuates the parallel resonance and blocks the series one with the utility and/or other loads. Thus, it offers more ability than other passive filtering methods [23] - [25]. Considering the expected cost of the HPF, Fig. 20 shows the expected total cost of the HPF compared to the other filters configurations under the same conditions, for all cases under study. It is obvious that HPF has an advantage as a reasonably competitive cost solution, especially when considering its ability to reduce the VTHD and the ITHD below the standard limits, and that harmonic-resonance risk is non-existent in HPF.
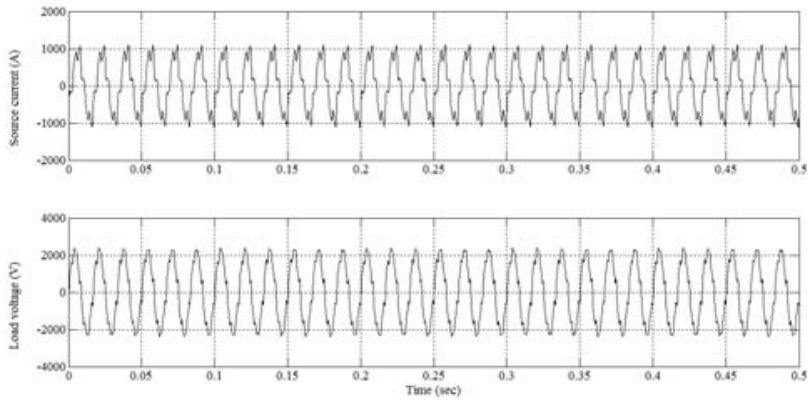

Fig.10. $I_{S}$ and $V_{L}$ waveforms, before compensation: Case II
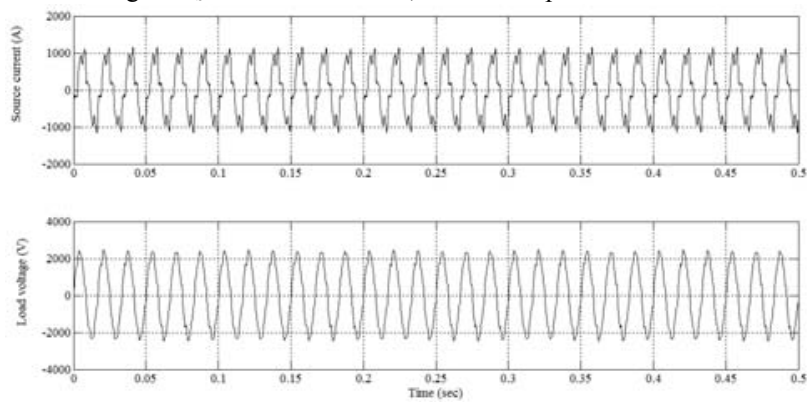

Fig.11. $I_{S}$ and $V_{L}$ waveforms, before compensation: Case IV
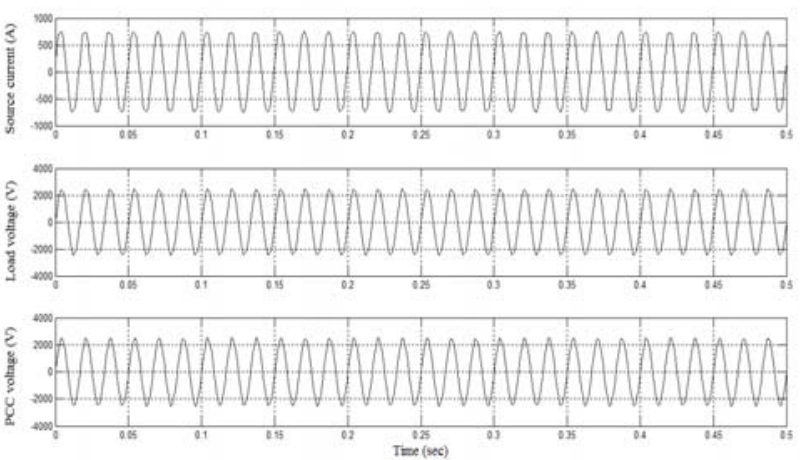

Fig.12. $I_{S}, V_{L}$, and $V_{P}$ waveforms after compensation: Case II
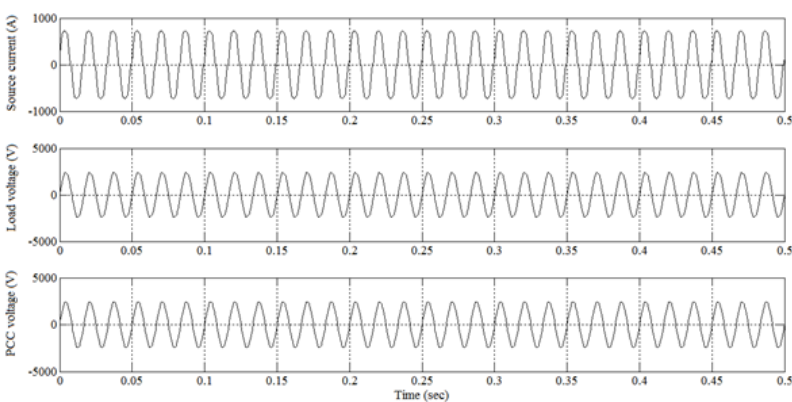

Fig.13. $I_{S}, V_{L}$, and $V_{P}$ waveforms after compensation: Case IV
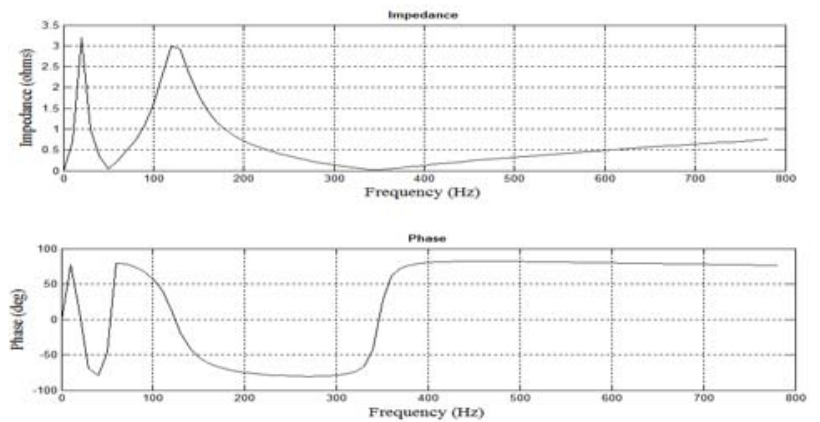

(a) Case II
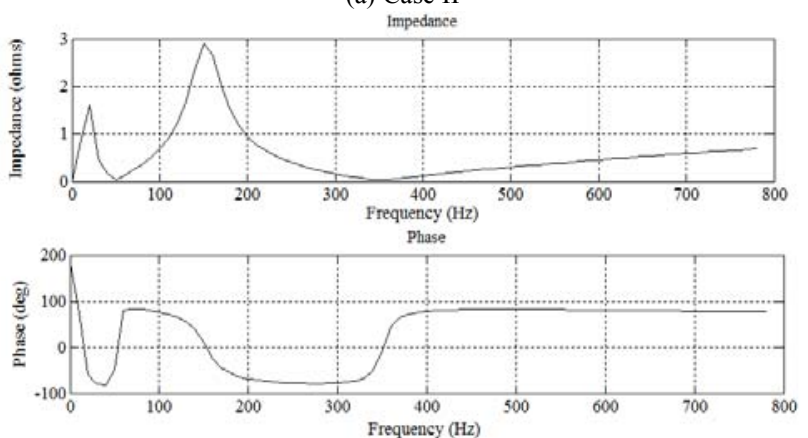

(b) Case IV

Fig.14. Impedance- frequency scans and phase-angle plots. (a) Case II, (b) Case IV 


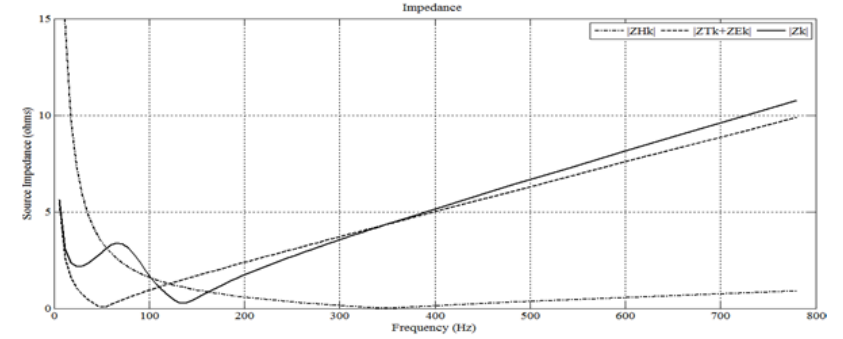

(a) Case II

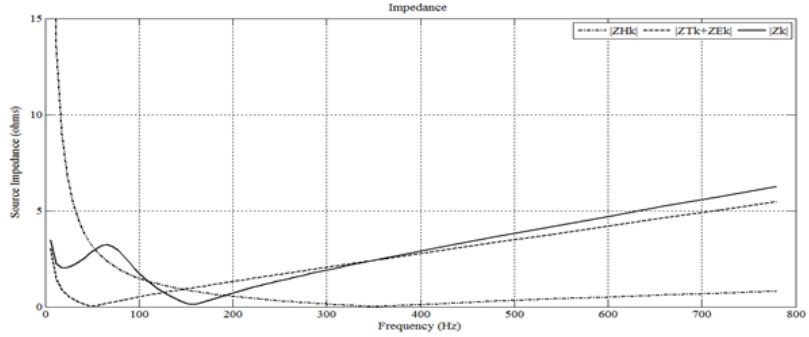

(b) Case IV

Fig.15. Equivalent source impedance- frequency scans (a) Case II, (b) Case IV

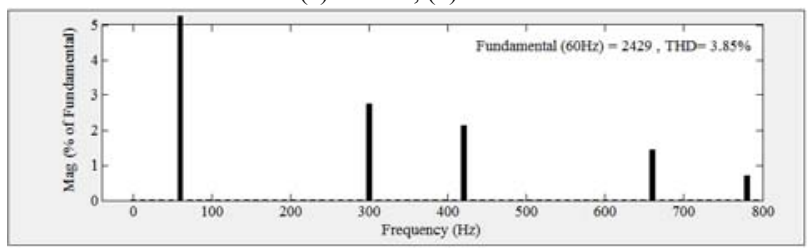

Fig.16. FFT analysis for the voltage at PCC: Case II

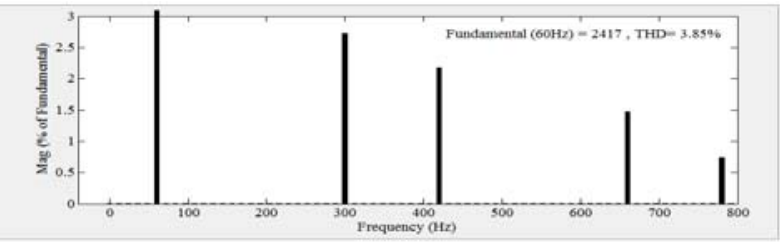

Fig.17. FFT analysis for the voltage at PCC: Case IV

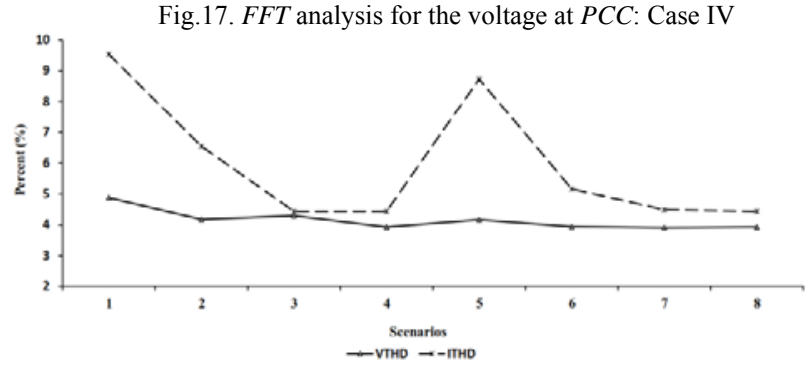

Fig.18. Variation in VTHD and ITHD at PCC

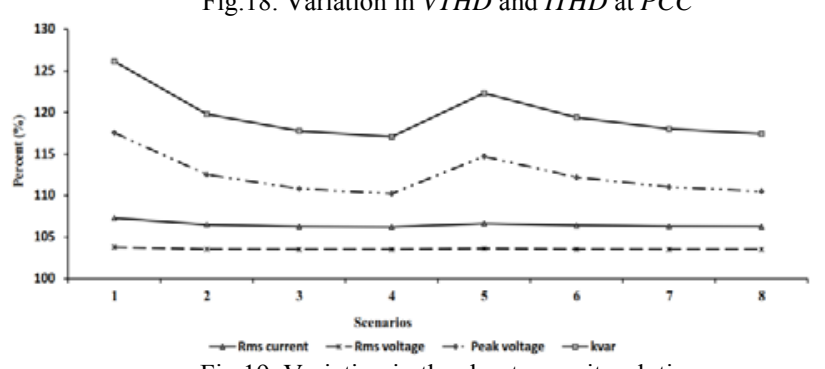

Fig.19. Variation in the shunt capacitor duties

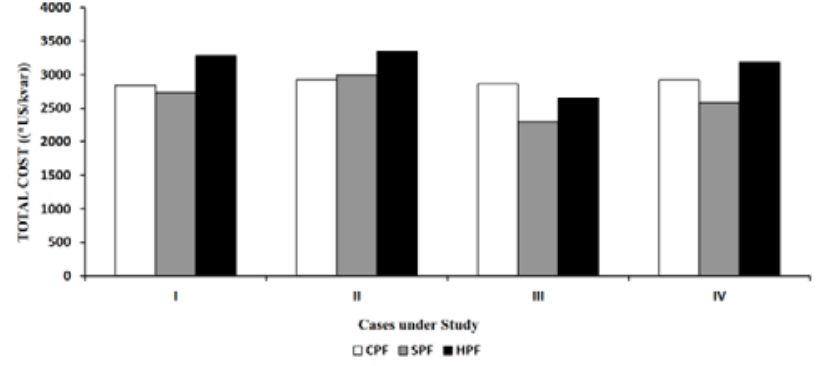

Fig.20. Expected cost indication

Comparing to the adaptive passive filter proposed in [3], it is evident that both filters have the advantages of no harmonic-resonance risk, insensitivity to source-impedance variations, and low cost. However, the choice of the appropriate solution needs some awareness of the various topologies, requirements of the distorted system, and nature of loads. For example, in order to satisfy the requirements of randomly varying loads; the adaptive passive filter will be the best choice because of its fast dynamic response. In other cases with low penetration of random nonlinear loads or invariable-load reactive-power demand, the proposed HPF will be the most appropriate scenario, and hence the importance of the provided method in finding alternatives.

As with any new topologies, there is a lot of room for development. For example, more attention should be paid for the nonlinear interaction between the network and the nonlinear equipments. A first approach towards this would be to model the network as Norton model or Harmonic Coupled Norton Equivalent Model, with appropriate correlation functions. These models are more accurate for a wider range of operating conditions than the commonly used "constant current" model, especially when the source voltage THD is on the order of $10 \%$ or more. Moreover, calculations concerning the voltage drop and the joule losses will be taken into account in the analysis. The findings of this research will be presented in a future paper.

\section{CONCLUSION}

Passive filters are still a growing concern for different customer sectors because they are considered to be powerful, easy, and economic solutions for power system harmonic suppression. Until now, harmonic suppression with fixed passive solutions has been carried out based only on mitigation of the harmonic voltage distortion, because it is not simple to meet acceptable harmonic current limits. However, the proposed HPF mitigates both currents' and voltages' harmonic pollution more effectively than other passive methods. The HPF can be considered as the first guard that stops the harmonic pollution propagation and offers isolation between the utility and the end-users. Consequently, it improves the performance efficiency and the life span of the electrical equipment. Finally, four cases are studied and the simulated results demonstrate the effectiveness of the proposed design procedure without any active strategy for complex control. 


\section{REFERENCES}

[1] A. F. Zobaa, M. M. Abdel-Aziz, and S. H. E. Abdel Aleem, "Comparison of shunt-passive and series-passive filters for DC drive loads," Electric Power Components \& Systems, vol. 38, no. 3, pp. 275-291, Mar. 2010.

[2] M.Z. El-Sadek, Power Systems Harmonic Filters, $1^{\text {st }}$ ed., Muktar Press, Assiut, Egypt, 2007.

[3] A. Hamadi, S. Rahmani, and K. Al-Haddad, "A hybrid passive filter configuration for VAR control and harmonic compensation," IEEE Trans. Ind. Electron., vol. 57, no. 7, pp. 2419-2434, Jul. 2010.

[4] S. Zheng, W. Chan, "Differential RF Phase Shifter with Harmonic Suppression, "IEEE Trans. on Industrial Electronics, vol. PP, no.99, pp. 1,2013

[5] M.S. Hamad, M.I. Masoud, B.W. Williams, "Medium-Voltage 12Pulse Converter: Output Voltage Harmonic Compensation Using a Series APF ,"IEEE Trans. on Industrial Electronics, vol. 61, no. 1, pp. 43-52, Jan 2014.

[6] S. H. E. Abdel Aleem, A. F. Zobaa and M. M. Abdel Aziz, "Optimal C-Type Passive Filter Based on Minimization of the Voltage Harmonic Distortion for Nonlinear Loads," IEEE Trans. Ind. Electron., vol. 59, no.1, pp. 281-289, Jan. 2012.

[7] Y. Xiao, J. Zhao, and S. Mao, "Theory for the design of C-type filter," in 11th Int. Conf. Harmonics and Quality of Power, ICHQP 2004, Lake Placid, New York, Sept. 12-15, 2004, pp. 11-15.

[8] A. B. Nassif, W. Xu, and W. Freitas, "An investigation on the selection of filter topologies for passive filter applications," IEEE Trans. Power Del., vol. 24, no. 3, pp. 1710-1718, Jul. 2009

[9] J. L. Zhou, A. L. Tits, and C. T. Lawrence, User's guide for FFSQP version 3.7: A FORTRAN code for solving optimization problems, possibly minimax, with general inequality constraints and linear equality constraints, generating feasible iterates, TR-92-107r5, Institute for Systems Research, University of Maryland, College Park, MD20742, USA, 1997.

[10] G. G. Richards, O. T. Tan, P. Klinkhachorn, and N. I. Santoso, "Costconstrained power factor optimization with source harmonics using LC compensators," IEEE Trans. Ind. Electron., vol. IE-34, no.2, pp. 266-270, May 1987.

[11] IEEE Standard for Shunt Power Capacitors, IEEE Standard 18-2002, 2002.

[12] Z. Hazem, and A. M. Hava, "Low pass broadband harmonic filter design," M.Sc., dissertation, Graduate school of natural and applied science, Middle East Technical Univ., Sept. 2005.

[13] J. W. Dixon, G. Venegas, and L. A. Moran, "A Series Active Power Filter Based on a Sinusoidal Current-Controlled Voltage-Source Inverter, " IEEE Trans. Ind. Electron., vol. 44, no. 5, pp. 612-620, Oct. 1997.

[14] M. F. McGranaghan, R. C. Dugan, and W. L. Sponsler, "Digital Simulation of Distribution System Frequency Response Characteristics," IEEE Trans. on Power App. and Systems, vol. PAS100, no. 3, pp. 1362-1369, Mar. 1981

[15] A.F. Zobaa, "Optimal multiobjective design of hybrid active power filters considering a distorted environment, "IEEE Trans. on Industrial Electronics, vol. 61, no. 1, pp. 107-114, Jan 2014.

[16] C. Chang, Y. Lin, Y. Chen, Y. Chang, "Simplified Reactive Power Control for Single-Phase Grid-Connected Photovoltaic Inverters ,"IEEE Trans. on Industrial Electronics, vol.PP, no.99, pp.1 , 2013

[17] M. M. Abdel Aziz, E. E. Abou El-Zahab, and A. F. Zobaa, "LC compensators based on cost minimization for nonlinear loads," 2003 Large Engineering Systems Conf. Power Engineering, LESCOPE'03, Montreal, Quebec, Canada, May 7-9, 2003, pp. 143-147.

[18] S. H. E. Abdel Aleem, A. F. Zobaa, and A. C. M. Sung, "On the economical design of multiple-arm passive harmonic filters," in 47th International Universities' Power Engineering. Conf., UPEC'12, Uxbridge, Middlesex, United Kingdom, Sep. 4-7, 2012, pp. 1-6.

[19] IEEE Recommended Practices and Requirements for Harmonic Control in Electrical Power Systems, IEEE Standard 519-1992, 1992.

[20] A.E. Emanuel, Power Definitions and the Physical Mechanism of Power Flow, $1^{\text {st }}$ ed., John Wiley, 2010.

[21] J. C. Das, "Passive Filters-Potentialities and Limitations," IEEE Trans. Ind. App., vol.40, no.31, pp.232-241, Jan. /Feb. 2004.

[22] L. Sainz and J. Balcells, "Harmonic Interaction Influence Due to Current Source Shunt Filters in Networks Supplying Nonlinear Loads," IEEE Trans. Power Del., vol.27, no.3, pp.1377-1385, Jul. 2012.
[23] S. Albatran, Y. Fu, A. Albanna, "Comprehensive Mathematical Description and Harmonic Analysis of Hybrid 2D-3D Space Vector Modulation,"IEEE Trans. on Industrial Electronics, vol. PP, no.99, pp.1, 2013.

[24] S. H. E. Abdel Aleem, and A.F. Zobaa, "Economical design of multiple-arm passive harmonic filters for an industrial firm - case study," in 15th Int. Conf. Harmonics and Quality of Power, ICHQP'12, Hong Kong, China, Jun. 17-20, 2012, pp. 438-444.

[25] S. H. E. Abdel Aleem and A. F. Zobaa, "Different Design Approaches of Shunt Passive Harmonic Filters Based on IEEE Std. 519-1992 and IEEE Std. 18-2002," Recent Pat. Elec. Eng., vol. 6, no.1, pp.68-75, 2013.

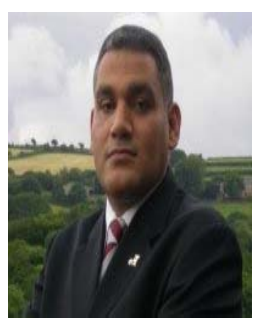

Ahmed Faheem Zobaa (M'02-SM'04) received the B.Sc.(Hons.), M.Sc., and Ph.D. degrees in electrical power and machines from Cairo University, Giza, Egypt, in 1992, 1997, and 2002, respectively. Currently, he is also a Senior Lecturer in power systems with Brunel University, Uxbridge, U.K. His main areas of expertise are lighting applications, power quality, (marine) renewable energy systems, grid integration, smart grids and energy management.

Dr. Zobaa is an Editor-in-Chief for the International Journal of Renewable Energy Technology.. He is a registered Chartered Engineer, Chartered Energy Engineer, European Engineer, and International Professional Engineer.. He is a Fellow of the Institution of Engineering and Technology, the Energy Institute of U.K., the Chartered Institution of Building Services Engineers, the Royal Society of Arts, and the Higher Education Academy of U.K. He is a senior member of the Institute of Electrical and Electronics Engineers.

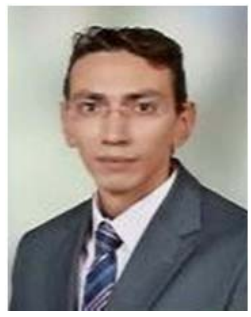

Shady Hossam Eldeen Abdel Aleem received the B.Sc. and M.Sc. and Ph.D. degrees in Electrical Power and Machines from the Faculty of Engineering, Helwan University, Helwan, Egypt, in 2002, and the Faculty of Engineering, Cairo University, Egypt, in 2010 and 2013 respectively. Currently, he is a Lecturer at 15th of May Higher Institute of Engineering. He is working in the field of electric machines, power quality, electric circuits, and engineering mechanics. Dr. Shady is member of Institute of Electrical and Electronics Engineers. He regularly reviews papers for many IEEE Transactions and journals in his areas of interest. He is author or co-author of many referred journal and conference papers. Areas of research include harmonic problems in power systems, power quality, photovoltaic energy, wind energy, marine energy, cables, electric machines, and engineering mechanics. 